\title{
El platanal o la nación. Representaciones sociales y prácticas en torno al plátano en la Colombia del sigloXIX
}

Resumen: A partir de la reflexión teórica sobre representaciones sociales, del análisis de textos de las élites y viajeros extranjeros y de las prácticas de producción y consumo del plátano [Musa paradisiaca], nos preguntamos cómo fue representado este producto entre 1780 y 1900 en las tierras calientes del bajo y medio río Magdalena. Argumentamos que el plátano fue un marcador de la frontera entre el "nosotros" [blanco, urbano, de las élites] y los "otros" [racialmente diversos, rurales, analfabetas]. Al ser representado como un "no-cultivo" tropical y cómplice del ocio de los ribereños, especialmente zambos, apareció como atávico, obstáculo para la civilización y forma de resistencia.

Palabras clave: plátano, representaciones sociales, prácticas, raza, élites, civilización.

\section{The plantain or the nation. Social representations and practices around the plantain in 19th century Colombia}

Abstract: Based on theoretical approaches to social representations, on the analysis of texts by elite and foreign travelers, and on production and consumption practices, we ask how plantain [Musa paradisiaca] was represented between 1780 and 1900, in the hot lands by the low and mid Magdalena river. We argue that plantain was a marker of the border between "Us" [white, urban, of the elite] and the "Others" [racially diverse, rural, illiterate]. Represented as a tropical "non-crop" and accomplice of riverside inhabitants' idleness, especially zambos', plantain appeared as atavistic, an obstacle to civilization, and a form of resistance.

Keywords: plantain, social representations, practices, race, elites, civilization.

\section{A banana ou a nação. Representações sociais e práticas em torno da banana na Colômbia do século XIX}

Resumo: A partir da reflexão teórica sobre representações sociais, da análise de textos de elites e viajantes estrangeiros e das práticas de produção e consumo da banana [Musa paradisiaca], nos perguntamos como esse artigo foi representado entre 1780 e 1900 nas terras quentes das partes baixa e média da região do rio Magdalena. Argumentamos que a banana foi um marcador da fronteira entre o "nós" [branco, urbano, das elites] e os "outro" [racialmente diverso, rural, analfabeto]. Ao ser representada como um "não-cultivo" tropical e como cúmplice do ócio dos ribeirinhos, principalmente zambos, pareceu como atávica, obstáculo à civilização e forma de resistência.

Palavras-chave: banana, representações sociais, práticas, raça, elites, civilização.

Cómo citar este artículo: Natalia Robledo Escobar, Laura Gutiérrez Escobary Nelsa De la Hoz, "El platanal o la nación: representaciones sociales y prácticas en torno al plátano en la Colombia del siglo XIX”, Trashumante. Revista Americana de Historia Socia/17 [2021]: 6-29. DOI: 10.17533/udea.trahs.n17a01

Fecha de recepción: 25 de febrero de 2020

Fecha de aprobación: 17 de septiembre de 2020

Natalia Robledo Escobar: Doctora en Antropología por la Universidad de los Andes. Profesora de cátedra de la Universidad Externado de Colombia. ORCID: 0000-0002-9462-4441.

Correo electrónico: natalia.robledo@uexternado.edu.co

Laura Gutiérrez Escobar: Doctora en Antropología por la Universidad de Carolina del Norte en Chapel Hill. Profesora asistente de la Pontificia Universidad Javeriana. ORCID: 0000-0002-2161-4031.

Correo electrónico: Imgutierrez@javeriana.edu.co

Nelsa De la Hoz: Doctora en Antropología por la Universidad de los Andes. Asesora de la Fundación Gaia Amazonas. . Correo electrónico: nj.de947@uniandes.edu.co 


\section{El platanal o la nación. Representaciones sociales y prácticas en torno al plátano en la Colombia del siglo XIX ${ }^{\star}$}

Natalia Robledo Escobar, Laura Gutiérrez Escobar y Nelsa De la Hoz

Plátano y tierra caliente: un asunto de representación

En 1857, el viajero Isaac Holton acusó al plátano de ser el "padre de la pereza". -Muchos otros autores del siglo XIX — nacionales y extranjeros - plantearon que el plátano contribuía al atraso de Colombia. Este punto de vista, presente en apelativos contemporáneos como los de "platanal" y "platanización", 2 utilizados para referirse de forma despectiva al país, contrasta con la popularidad actual de este alimento. ${ }^{3}$ En efecto, la Musa paradisiaca — que a diferencia del banano (Musa sapientum) se suele comer cocinada - es la base de una gastronomía diversa que acude al plátano verde, pintón y maduro para preparar recetas saladas y dulces, algunas de las cuales, como el cayeye y el aborrajado, siguen estando marcadas en términos étnicos y raciales.

La agricultura y la alimentación están mediadas por relaciones de poder intra e intergrupales. El estatus y la capacidad que se les atribuye a los alimentos de nutrir

* Esta investigación fue financiada por las convocatorias 512 y 528 del Consejo Nacional de Ciencia y Tecnología (Colciencias). Agradecemos los valiosos aportes de los evaluadores anónimos y de los investigadores Sergio Méndez, Alberto Gómez y Marta Villegas.

1. Isaac F. Holton, La Nueva Granada: veinte meses en los Andes (Bogotá: Ediciones del Banco de la República, 1981) 21.

2. Aunque nos centramos en el plátano, es importante mencionar el concepto de república bananera, que remite a la influencia del imperialismo estadounidense y particularmente de la United Fruit Company en países caribeños marcados por la pobreza, la corrupción y la inestabilidad política. Según John Soluri, "la frase metafórica adquirió un poder discursivo importante, funcionando como explicación y justificación para los conflictos, la pobreza y las intervenciones políticas de los EE.UU., temas centrales de la historia centroamericana del siglo XX". John Soluri, Culturas bananeras: producción, consumo y transformaciones socioambientales (Bogotá: Siglo del Hombre Editores / Universidad Nacional de Colombia, 2013) 28.

3. El plátano es el alimento más producido en Colombia, con 4,8 millones de toneladas en 2019 destinadas mayoritariamente al mercado interno y al autoconsumo. https://sioc.minagricultura. gov.co/Platano/Documentos/2020-03-31\%20Cifras\%20Sectoriales.pdf (25/01/2021) 
y contribuir al desarrollo socioeconómico varían históricamente. Algunos incluso han sido referentes en la construcción de representaciones sociales de territorios y poblaciones. ${ }^{4}$ Sin duda, el plátano es uno de ellos.

La importancia de este alimento en la dieta nacional, las identidades regionales y la subsistencia de las poblaciones de las tierras calientes y templadas, así como las imágenes diversas y a menudo racializadas que se han producido sobre él, invitan a reflexionar sobre su papel en las discusiones en torno a la construcción y el progreso de la nación.

Este artículo analiza cómo fue representado el plátano de las tierras calientes del actual territorio colombiano en textos de miembros de las élites y viajeros extranjeros entre 1780 y $1900 ;{ }^{5}$ asimismo, se refiere a las prácticas de cultivo y de consumo del plátano por parte de los habitantes de las riberas de los ríos. Nos centramos en el bajo y medio Magdalena por ser este el recorrido obligado de los viajeros que salían o entraban al país y por abarcar una parte considerable de los relatos. Allí muchos pobladores combinaban las actividades de subsistencia con la boga en embarcaciones artesanales.

El periodo de análisis, que comienza con las reformas borbónicas en el virreinato de la Nueva Granada y concluye con la decadencia de la producción tabacalera y el surgimiento de la economía cafetera de exportación, estuvo atravesado por el interés en modernizar las sociedades rurales y la agricultura. Durante la colonia y la república, las élites gobernantes buscaron exportar minerales y vegetales - como alimentos, materias primas, productos medicinales y suntuarios - en su mayoría extraídos en las tierras calientes, mejor conectadas con los mercados internacionales. En la segunda mitad del siglo XIX, con los esfuerzos de los gobiernos liberales por poner al país en la senda del libre cambio, estas actividades extractivas se combinaron con un progresivo, aunque precario, desarrollo de la agricultura hacendataria, primero con el tabaco y luego con el café. El auge agroexportador generó procesos de colonización de vertiente - sobre todo en Cundinamarca y Antioquia- y un aumento poblacional en las zonas bajas. A la par, los habitantes rurales mantuvieron una economía de subsistencia basada en la pesca, la caza, la recolección y la agricultura. ${ }^{6}$

Por otra parte, este fue un periodo en el que la raza jugó un papel fundamental en la construcción de las representaciones de la nación. ${ }^{7}$ Pese a tratarse de un concepto escasamente definido, con múltiples significados desde su aparición en

4. Carolyn Korsmeyer, ed., The Taste Culture Reader. Experiencing Food and Drink (Oxford / New York: Berg Publishers, 2005).

5. El plátano se da en tierras calientes y templadas (entre los 0 y los 2000 m.s.n.m.), pero la representación del de tierra templada es más matizada.

6. José Antonio Ocampo, Colombia y la economía mundial, 1830-1910 (Bogotá: Siglo XXI Editores, 1984).

7. Álvaro Villegas Vélez, "Heterologías y nación: proyectos letrados y alteridad radical en la Colombia decimonónica”, Signo y Pensamiento 27.53 (2008): 24-37. 
los encuentros imperiales del periodo moderno temprano, ${ }^{8}$ las razas fueron consideradas como entidades fijas con características culturales y morales intrínsecas. Con la Independencia y en el marco de los ideales republicanos, comenzó a construirse lo que Marixa Lasso ha llamado el mito de la armonía racial, apoyado en la exaltación del mestizaje. ${ }^{10}$ La Constitución de Cúcuta y las siguientes desmontaron el sistema colonial de castas al promulgar la igualdad ante la ley, con excepción de los negros esclavos.

No obstante, la celebración del mestizaje implicó la aspiración al blanqueamiento, y la raza siguió siendo utilizada para jerarquizar a los grupos humanos, además de circunscribirlos a provincias o regiones. La formación del Estado nacional se enmarcó, así, en la invención de una geografia que regionalizó la nación y racializó las regiones, con lo que se les asignó un determinado grado de moralidad, orden y capacidad de progreso. ${ }^{11}$ Según Julio Arias Vanegas, “el ejercicio diferenciador pasó por una colonialidad interna, en la que el racialismo sustentaba un orden jerárquico y naturalizador de las diferencias poblacionales y espaciales". ${ }^{12}$ Así, al tiempo que las élites nacionales exaltaron las similitudes entre los colombianos, subrayaron sus diferencias e intentaron imponer sobre las regiones las características —más imaginadas que reales - del mundo andino: su supuesta civilización y blancura. ${ }^{13}$

Argumentamos que el plátano fue representado como un producto de bajo estatus y racializado que sirvió como un marcador importante de la frontera entre el "nosotros" (blanco, urbano, educado, de las élites) y los "otros" (racialmente diverso, predominantemente rurales, sin educación formal, no pertenecientes a las élites). La diferencia entre las tierras frías — que evocaban las europeas- y las tierras calientes, consideradas las más atrasadas, fue simbolizada por algunas fuentes a partir del contraste que establecieron entre las prácticas de producción y consumo del plátano y del trigo. En ello, Francisco José de Caldas fue elocuente:

8. Nancy P. Appelbaum, Mapping the Country of Regions. The Chorographic Commission of NineteenthCentury Colombia (Chapel Hill:The University of North Carolina Press, 2016).

9. Jaime Jaramillo Uribe, "La visión de los otros. Colombia vista por observadores extranjeros en el siglo XIX”, Historia Crítica 24 (2002): 7-21. DOI: 10.7440/histcrit24.2002.01.

10. Marixa Lasso, Myths of Harmony. Race and Republicanism during the Age of Revolution, Colombia 1795-1831 (Pittsburgh: University of Pittsburgh Press, 2007).

11. Nancy P. Appelbaum, Dos plazas y una nación. Raza y colonización en Riosucio, Caldas, 1846-1948 (Bogotá: Instituto Colombiano de Antropología e Historia / Universidad de los Andes / Universidad del Rosario, 2007);Villegas Vélez 24-37.

12. Julio Arias Vanegas, Nación y diferencia en el siglo XIX colombiano. Orden nacional, racialismo y taxonomías poblacionales (Bogotá: Ediciones Uniandes, 2005) xviii.

13. Según Jorge Orlando Melo, "en el siglo XIX, en especial, la civilización europea asumió en forma creciente una visión de sí misma como encarnación del destino humano, que habría de extenderse desde los países industriales y capitalistas hasta la periferia salvaje". Jorge Orlando Melo, "La mirada de los franceses: Colombia en los libros de viaje durante el siglo XIX", noviembre de 2001. http://jorgeorlandomelo.com/mirada_franceses.htm (25/06/2020). 
"donde empieza a prosperar el trigo con utilidad del labrador, acaba la vegetación del plátano (musa)". ${ }^{14}$

Asimismo, argumentamos que la representación del plátano, ambigua, pero fundamentalmente negativa, estuvo atravesada por las imágenes dominantes del trópico, de las formas de agricultura consideradas menos civilizadas y de los habitantes no urbanos de tierra caliente. Con frecuencia, las fuentes concibieron el plátano como lo que denominamos un "no-cultivo", es decir, un alimento situado entre la recolección y la agricultura debido a su reproducción vegetativa, ${ }^{15}$ escasa necesidad de cuidados y alta productividad. Encarnaba lo peor del trópico —en su variante selvática y de tierra caliente- y de los sujetos no-blancos, especialmente los zambos. Al menos dos consecuencias se derivaron de esto: primero, el plátano apareció como una talanquera para la civilización de las tierras calientes y su integración al proyecto nacional. El "platanal o la nación" condensa esta tensión que preocupaba a las élites entre vegetar en el atraso o cultivar la civilización. Segundo, su producción y consumo en estas regiones constituyó una forma de resistencia, aunque desconocemos si fue planeada.

Nuestro análisis parte de la reflexión teórica sobre las representaciones sociales, planteada desde la psicología social, la antropología y los estudios culturales. Entendemos las representaciones sociales como una red de conceptos e imágenes, cuyos contenidos cambian en el tiempo y en el espacio. ${ }^{16}$ Estas dependen del sistema de creencias del grupo que las produce, pero están permeadas por lo individual. Son, además, generalizantes, puesto que sirven como moldes en los que se intenta encajar a todos los individuos u objetos incluidos en la categoría representada. ${ }^{17}$

Destacamos cuatro características de las representaciones sociales: primero, son construcciones sociales, aunque se asumen como verdaderas e incluso como científicas. Segundo, son heterogéneas, dinámicas y en muchos casos contradictorias. Tercero, si bien todos estamos implicados en su uso y producción, ${ }^{18}$ el Estado, los medios de comunicación y las élites son particularmente influyentes. ${ }^{19}$ Cuarto,

14. Francisco José de Caldas, "Memoria sobre la nivelación de las plantas que se cultivan en la vecindad del Ecuador", Obras completas de Francisco José de Caldas. Publicadas por la Universidad Nacional de Colombia como homenaje con motivo del sesquicentenario de su muerte (Bogotá: Imprenta Nacional, 1966) 341. Cursiva en el original.

15. Se propaga mediante la siembra de partes vegetativas de la planta madre.

16. Serge Moscovici, "Notes towards a description of Social Representations", European Journal of Social Psychology 18 (1988): 211-250.

17. Natalia Robledo Escobar,"Labrar para civilizar y ser civilizado: representaciones sociales sobre el campo, la agricultura y los agricultores del actual territorio colombiano en el periodo comprendido entre 1780 y 1866" (Tesis de doctorado en Antropología, Universidad de los Andes, 2017).

18. Stuart Hall, “The Work of Representation”, Representation: Cultural Representations and Signifying Practices, ed. Stuart Hall (Londres: Sage Publications, 1997) 13-74.

19. Eleni Andreouli y Xenia Chryssochoou, "Social Representations of National Identity in Culturally Diverse Societies", The Cambridge Handbook of Social Representations, eds. Gordon Sammut y otros (Cambridge: Cambridge University Press, 2015) 309-322. 
hacen parte de la longue dureé — sensu Braudel_- pues su sentido general — lo que podríamos llamar su núcleo- suele cambiar lentamente.

En este trabajo nos centramos en un proceso de larga duración que permite identificar tendencias, pero reduce la atención a los detalles. Esta mirada panorámica es pertinente dado que, pese a las importantes transformaciones del discurso racial y ambiental en el periodo, la representación hegemónica de las tierras calientes y sus habitantes, especialmente los zambos ${ }^{20}$ siguió ratificando la enorme distancia simbólica que supuestamente las separaba de la civilización. Es pertinente también porque, aunque el bajo y medio Magdalena fueron un escenario importante del auge agroexportador de la segunda mitad del siglo XIX, el plátano se mantuvo circunscrito al mercado interno y su producción siguió siendo pensada en términos racializados al ser predominantemente asociada con lo zambo.

Nos centramos en imágenes textuales, provenientes de fuentes históricas particularmente ricas en descripciones de las tierras calientes y de sus habitantes. La descripción juega un papel fundamental, pero no siempre reconocido, en el acto de representar, pues le permite al lector "pintar" en su cabeza lo que lee y transformar una imagen textual en una mental que reelabora a partir de representaciones previas. En el caso de las imágenes textuales aquí analizadas, el acto de representar se amparó en la autoridad de haber estado allí, lo que produjo un "efecto realidad" 21 que las hizo aparecer como inequívocamente verdaderas.

Las fuentes consultadas se mostraron convencidas de la verosimilitud de sus descripciones y de estar escribiendo desde la razón y la neutralidad. No obstante, reflejaron sus sociedades de origen y sus puntos de vista estuvieron sesgados por su posición social privilegiada, como hombres blancos altamente educados y pertenecientes a las élites o conectados con ellas; su mirada predominantemente andina; las condiciones de sus viajes — muchas veces sus tiempos de permanencia fueron cortos y la escritura fue tardía- y los intereses que representaron.

La Independencia generó una renegociación de las relaciones entre las antiguas colonias españolas y los países europeos. Las autoridades republicanas vieron en estas relaciones la posibilidad de "civilizar el territorio", atraer inversiones y obtener empréstitos. Las potencias europeas, por su parte, buscaron expandir su dominio socioeconómico y político a un continente que desde su "descubrimiento" y por tres siglos había estado vedado. ${ }^{22}$ En este contexto, los viajeros nacionales y extranjeros contribuyeron a reconocer a esos otros con los que se pretendía establecer nuevos nexos comerciales y culturales, y a fijar la jerarquización de lugares y poblaciones. En el grabado El champán, de Ramón Torres Méndez, se hace patente la distinción entre los bogas y los viajeros en aspectos como la semidesnudez y la

20. Esto se debe en gran medida a que la mezcla de indio y negro no conducía al blanqueamiento.

21. Peter Burke, Visto y no visto. El uso de la imagen como documento histórico (Barcelona: Crítica, 2001) 165.

22. Mary Louise Pratt, Imperial Eyes. Travel Writing and Transculturation (Londres / Nueva York: Routledge, 1994). 
actitud de trabajo, por parte de los primeros, y la vestimenta elegante y la actitud de ocio, por parte de los segundos. ${ }^{23}$

Los relatos de viaje fueron fundamentales para conocer las tierras ardientes que habían escapado a los esfuerzos civilizatorios. Sirvieron también para insertarlas en un espacio simbólico común que permitiera integrarlas al proyecto nacional e impulsar su transformación según los intereses del Estado. Esa transformación requería, según varios observadores de la época, prescindir del plátano por su efecto perverso en poblaciones de por sí reacias a salir de una vida en la que más que la cultura imperaba la naturaleza. De ahí que fuera representado de forma negativa, pese a las bondades que se le atribuían.

El artículo explora, en cuatro apartados, varias imágenes ligadas al plátano que son transversales al periodo de estudio y que lo presentan como un producto que encarnaba la feracidad y la fertilidad del trópico; símbolo del ocio y la indolencia racializada; no-cultivo, más cercano a la recolección que a la producción, y talanquera para la civilización de las tierras calientes y sus habitantes, en cuanto sostén de su independencia económica.

\section{El plátano o la quintaesencia de la sensualidad y la fertilidad tropical}

Muchas de las críticas a la América tropical durante la Colonia estuvieron sustentadas en la falta de estaciones. Para la mirada europea, la eterna primavera no incentivaba la previsión ni el ahorro necesarios para la civilización. Al no tener que enfrentar el invierno, se podía llevar una vida de ocio y trabajo holgado sin preocuparse por almacenar alimentos, puesto que la naturaleza los brindaba diariamente. La vida se reproducía incesantemente y los recursos eran tan abundantes que tenían un efecto de parálisis en las actividades económicas.

De acuerdo con Nancy Stepan, desde el siglo XVIII tres disciplinas científicas contribuyeron a la definición del trópico a partir de las observaciones sobre la naturaleza, las poblaciones y las enfermedades de América y de otros territorios que habían sido - o estaban siendo- colonizados por los europeos: la historia natural con la taxonomía de la flora y la fauna; la antropología con sus clasificaciones raciales, y la medicina, que explicó las enfermedades a partir de variables de lugar y clima. Según Stepan, en el siglo XIX se cristalizó esta mirada científica de América como un "otro" radicalmente diferente de Europa. ${ }^{24}$

En contraste con esta mirada homogénea del trópico, las élites criollas ilustradas plantearon que las condiciones medioambientales en América eran diversas. A falta de estaciones había pisos térmicos que, si bien no obligaban a planear y almacenar a los niveles europeos, permitían soñar con el florecimiento de la civilización en

23. Ramón Torres Méndez, "El champán. Navegación por el Magdalena" (grabado, litografia iluminada: 25,8 x 34,1 cm), Bogotá, 1851. BLAA, Bogotá, Colección de Arte, número de registro AP3624. https://www.banrepcultural.org/coleccion-de-arte/obra/el-champan-navegacion-pormagdalena-ap3624 (25/01/2021).

24. Nancy Leys Stepan, Picturing tropical nature (London: Reaktion Books, 2001) 16-17. 
algunos de ellos. La geografía quedó entonces dividida en tres grandes "tierras": la caliente, que abarcaba de los 0 a los cerca de 600 m.s.n.m.; la templada, de los 1,000 a los 2,000 m.s.n.m., y la fría, desde los 2,000 m.s.n.m. hasta las nieves perpetuas. ${ }^{25}$

De acuerdo con Felipe Martínez Pinzón, "las élites criollas andinas localizaron la civilización en un lugar sedentario a una cierta altura de 'clima benéfico' en asentamientos supuestamente habitados por blancos o mestizos hispanizados". ${ }^{26}$ La representación de estos lugares, que no eran otros que las tierras frías y particularmente el altiplano cundiboyacense, refleja lo que Martínez Pinzón llama un pensamiento "antitropical" que contribuyó a naturalizar y justificar el proyecto político y económico de las élites.

Los naturalistas Francisco José de Caldas y Alexander von Humboldt fueron determinantes en la construcción de la mirada andinista de finales del siglo XVIII e inicios del XIX, según la cual la civilización e incluso el potencial para alcanzarla aumentaban con la altitud. Esto implicaba no solo que la civilización era posible en América y que ya tenía algún nivel de desarrollo, sino también que la distancia civilizatoria entre América y Europa era variable. Muchos autores llevaron la perspectiva andinista hasta el determinismo geográfico y ambiental al afirmar que los pisos térmicos influían directamente en las condiciones físicas y morales de la población y, por lo tanto, en su capacidad de conocimiento. Dicha influencia, sin embargo, variaba para cada una de las razas.

En el punto más bajo de la escala civilizatoria estaban las tierras calientes. No solo eran las más incivilizadas sino que para muchos, especialmente para los letrados que escribieron antes de mediados del siglo XIX, su potencial civilizador era limitado. Esto se debía a que no se parecían a Europa y ofrecían lo peor del trópico. Con respecto a lo primero, no solo habían sido resistentes al dominio de la biota mixta europea, ${ }^{27}$ sino que los adelantos modernizantes estaban ausentes. En cuanto a lo segundo, transmitían una imagen engañosa. En un principio producían "admiración poética por la suntuosidad de sus bosques y la belleza de su cielo", 28 pero el desencanto sobrevenía al entrar en contacto con su peligrosa naturaleza, las enfermedades tropicales y las gentes "degeneradas", descritas de forma racializada e hipersexualizada.

Las regiones bajas eran hogar de alimañas y fieras salvajes. Son abundantes las referencias a la fauna desbordada, agigantada, peligrosa y hasta monstruosa. Esto, sumado a la proliferación de enfermedades como fiebres, hidropesía, paludismo,

25. En la delimitación de Humboldt y Bonpland no queda clara la clasificación de las tierras ubicadas entre los 600 y los 1,000 m.s.n.m. Alexander von Humboldt y Aimé Bonpland, Ideas para una geografía de las plantas más un cuadro de la naturaleza de los países tropicales (Bogotá: Jardín Botánico José Celestino Mutis, 1985) 137 y 141.

26. Felipe Martínez Pinzón, Una cultura de invernadero: trópico y civilización en Colombia (1808-1928) (Madrid: Iberoamericana, 2016) 15.

27. Germán A. Palacio Castañeda, Fiebre de tierra caliente. Una historia ambiental de Colombia, 18501930 (Bogotá: Universidad Nacional de Colombia / ILSA, 2006) 60.

28. Medardo Rivas, Los trabajadores de tierra caliente (Bogotá: Incunables, 1983) 200. 
malaria y carate, constituía un obstáculo al poblamiento. El abogado y empresario Miguel Samper lamentó que "la población no baja de las faldas y mesas de la cordillera sino con lentitud y precaución, porque allí donde está la riqueza fácil, la muerte ha establecido también su imperio. Nuestras cordilleras son verdaderas islas de salud rodeadas por un océano de miasmas". ${ }^{29}$

La flora de las tierras calientes también era exuberante y vigorosa, y los cultivos daban frutos en tiempos récord. La caña de azúcar daba tallos de un "grosor extraordinario" a los seis meses de plantada y duraba para "siempre si se tiene cuidado de limpiarla". El cacao producía "abundantes mazorcas a los tres o cuatro años" y duraba sesenta años. El plátano tomaba un par de años en producir y duraba de 15 a 20 años, aunque por su reproducción vegetativa podía ser "eterno". 30

La naturaleza de las tierras calientes fue descrita como fértil e incluso lujuriosa, lo cual ratificó la idea de exceso. Desde esta perspectiva, la prodigalidad de estas tierras resultaba ingobernable - la manigua todo lo devoraba- y desincentivaba el trabajo. La supuesta sobreabundancia de recursos vegetales y de productos de caza y pesca, que desalentaba el espíritu de empresa, fue vista como una de las causas principales del ocio de los habitantes de las tierras bajas.

Según las fuentes consultadas, el calor, la humedad, la quietud del aire, el anegamiento de los suelos y la materia orgánica en descomposición eran causa de tanta opulencia natural. Auguste Le Moyne, diplomático francés que residió en el país entre 1828 y 1839, explicó que en las regiones tropicales "el calor combinado con lo húmedo de los pantanos constituye la fuente inagotable de una fecundidad sin límites para las grandes especies arbóreas y para el desarrollo de las especies animales". 31

Las tierras calientes, en su mayoría selváticas, fueron representadas como la quintaesencia del trópico. De toda la flora que albergaban, el plátano representó como ninguna otra planta comestible la vida desbordada que supuestamente lo caracterizaba. De nada valió que no fuera americano. Si bien era originario del sudeste asiático, ${ }^{32}$ su rápida adaptación y proliferación en América, así como su importancia en la alimentación de las castas, lo hicieron pasar por endémico entre muchos observadores de la época. ${ }^{33}$

La facilidad con la que se daba, el tamaño de sus racimos, el largo tiempo de producción de cada planta y su reproducción vegetativa hicieron del plátano una

29. Miguel Samper, La miseria en Bogotá y otros escritos (Bogotá: Biblioteca Universitaria de Cultura Colombiana, 1969) 16.

30. Agustín Codazzi, Geografía física y política de la Confederación Granadina, eds. Guido Barona Becerra y otros, vol. I, t. II (Bogotá: Universidad Nacional de Colombia, 2002) 146.

31. Augusto Le Moyne, Viaje y estancia en la Nueva Granada (Bogotá: Ediciones Guadalupe, 1969) 41.

32. Según Gregorio Saldarriaga, el plátano fue "una planta introducida y propagada por los españoles en el continente americano, dado que así lo indican las fuentes tempranas y que hay ausencia de registros del plátano en hallazgos arqueológicos que den cuenta del periodo previo a la llegada de los europeos a América". Gregorio Saldarriaga, "Musas en el paraíso: apropiaciones del plátano por parte de españoles e indígenas. Nuevo Reino de Granada, siglos XVI y XVII", Revista do Instituto Histórico e Geográfico do Pará 7 (2020): 16.

33. Víctor Manuel Patiño, "Plátanos y bananos en América equinoccial", Revista Colombiana de Antropología VII (1958): 297-337. 
metáfora de la fertilidad tropical. El grabado Étude de bananier (Musa paradisiaca), diseñado por A. de Neuville con base en un croquis de Charles Saffray (1869), presenta una analogía entre la sensualidad de una mujer - expresada en el escote, el collar y la postura - y la fecundidad del plátano. ${ }^{34} \mathrm{El}$ médico francés Charles Saffray, quien llegó al país en 1861, explicó que "entre los vegetales herbáceos no hay ninguno que rivalice con esta planta, generosa, por sus bellas formas y su gracia" ${ }^{35}$ Por su parte, Alfred Hettner, un geógrafo alemán que permaneció en Colombia entre 1882 y 1884, explicó que el plátano, categoría en la que incluyó a la Musa paradisiaca y a la sapientum, era "símbolo del idilio tropical, por la facilidad de su cultivo y la excelencia de la variedad de manjares que con la fruta deliciosa se pueden preparar". ${ }^{36}$

Por otra parte, su forma fálica - el "grueso calibre" con el que Briceño describió en 1866 los plátanos que le sirvieron en un convite - ${ }^{37}$ facilitaba su asociación con la fecundidad hipersexualizada de los calentanos, y particularmente de los negros y los zambos. Al darles sustento a personas ociosas, estas se reproducían copiosamente y llenaban las selvas de seres mal tenidos que, a su vez, hacían lo mismo gracias al plátano. Estos dos apartes de la novela costumbrista Manuela, de Eugenio Díaz Castro, ilustran el asunto:

Don Demóstenes [...] se estaba meciendo en su hamaca con ese grado de pereza que es el opio del estanciero del Magdalena [...], muy seguro de que el pescado solicita la carnada del anzuelo, que el venado busca la trampa del lazo y los vástagos de plátano paren, según la metáfora de que usan los calentanos, para expresar la fecundidad con que se multiplican. ${ }^{38}$

Pues otros años he ido a Fusagasugá, que es magnífico por su temperatura, por sus aguas, por su gente, por sus bellas sabanas y sus célebres quintas.

- Pues eso sí no tenemos por aquí.

—Cierto, porque las tierras, como este distrito, húmedas [...], son buenas para producir mucha caña y mucho plátano, pero no mucha vida. ${ }^{39}$

En estas citas aparece lo positivo y lo negativo de la representación del plátano como producto tropical por excelencia. Por un lado, la fecundidad del alimento, con su capacidad para reproducir un modo de vida marcado por la quietud. Por otro lado, la idea de que hay tierras que, si bien producen "mucha caña y mucho plátano", no son aptas para producir "mucha vida", entendida como la vida civilizada.

34. BLAA, Bogotá, Colección de Arte. https://www.banrepcultural.org/galeria-historica/185.htm $(25 / 01 / 2021)$.

35. Charles Saffray, Viaje a Nueva Granada (Bogotá: Ministerio de Educación Nacional, 1948) 154.

36. Alfred Hettner, Viajes por los Andes colombianos (1882-1884) (Bogotá:Talleres Gráficos del Banco de la República, 1976) 44.

37. A. Briceño Briceño, "La siembra del trigo", Museo de cuadros de costumbres, t. 3 (Bogotá: Biblioteca Banco Popular, 1973) 331-335.

38. Eugenio Díaz Castro, Manuela (Bogotá: Panamericana, 2004) 96.

39. Díaz Castro 20. 


\section{Padre de la pereza, sobreabundancia ociosa}

Durante la colonia los descendientes de europeos se concentraron en las cordilleras, los indígenas permanecieron en sus asentamientos y los negros fueron esclavizados y destinados especialmente al laboreo de las minas y a la colonización de las tierras bajas. ${ }^{40} \mathrm{~A}$ partir de esta realidad fue madurando "la idea de que cada raza tenía su 'geografía inevitable y fatal' y de que en la combinación de los factores raciales y climáticos que definían cada región estaban las claves del nivel de civilización y progreso que tal región pudiera alcanzar". ${ }^{4}$

La geografía de las razas tomó la forma de una topografia moral. ${ }^{42}$ Las tierras bajas fueron representadas como el hábitat de las razas más salvajes, mientras que las altas aparecieron como el hogar de la raza superior: la blanca. Esta representación tenía puntos de encuentro con la escatología cristiana, según la cual desde la Tierra se ascendía al Cielo y se descendía al Infierno. ${ }^{43}$ La jerarquía climática radicalizó las diferencias y siguió una colonialidad del poder que después de la Independencia probó ser un obstáculo para la construcción de la nación. ${ }^{44}$

Además de los efectos nocivos para la salud, se planteó que el calor causaba estados de sopor e inactividad. A finales del siglo XVIII, fray Joaquín de Finestrad, un capuchino enviado a pacificar las regiones involucradas en la Revolución de los Comuneros, afirmó que el calor "causa que el reprensible vicio de la ociosidad domine en los pueblos y penetre hasta los lugares más santos, quedando en inacción los entendimientos menos preocupados". ${ }^{5}$ Lo que el fraile omitía era que los entendimientos "más preocupados" estaban exentos de realizar trabajos fisicos debido a su blancura. Jean-Baptiste Boussingault, químico e ingeniero de minas francés que participó en la misión Zea en la década de 1820, se mostró convencido de que en las tierras cálidas "el hombre no es sino momentáneamente activo, por una sobreexcitación, para caer enseguida en su indolencia habitual". ${ }^{46}$ Saffray "comprendió" el ocio de los habitantes por el calor y justificó la ingesta de ron para contrarrestar "la influencia depresiva del clima". ${ }^{77}$

Quizás el más honesto fue el sueco Carl August Gosselman, quien recorrió el país entre 1825 y 1826. Gosselman reconoció que "ellos" (¿los viajeros? ¿los

40. Cristina Rojas, Civilización y violencia. La búsqueda de la identidad en la Colombia del siglo XIX (Bogotá: Pontificia Universidad Javeriana / Editorial Norma, 2001) 82.

41. María Camila NietoVillamizar y María Riaño Pradilla, Esclavos, negros libres y bogas en la literatura del siglo XIX (Bogotá: Ediciones Uniandes, 2011) 97-98.

42. Michael Taussig, Chamanismo, colonialismo y el hombre salvaje. Un estudio sobre el terror y la curación (Bogotá: Editorial Norma, 2002).

43. Taussig.

44. Arias Vanegas 70 y ss.

45. Fr. Joaquín de Finestrad, El vasallo instruido en el estado del Nuevo Reino de Granada y en sus respectivas obligaciones (Bogotá: Universidad Nacional de Colombia, 2001) 93.

46. Jean Baptiste Boussingault, Memorias, vol. 2 (Bogotá: Banco de la República, 1985) 89.

47. Saffray, Viaje a Nueva Granada 58. 
europeos? ¿los blancos?) añoraban la vida de descanso que provocaba el calor, pues "pocas veces se puede realizar algo en este calor infernal, por lo que la mayor parte del tiempo se pasa sin hacer nada, en la casa o en la hamaca o afuera haciendo visitas. El tiempo lo ocupa la gente en charlar sin descanso, lo que para muchos, también para nosotros, es una forma de pasar la vida verdaderamente envidiable". ${ }^{48}$

Sin duda, el plátano jugaba un papel fundamental en esta vida de ocio. En palabras de Holton, "es inútil entrar a un platanal esperando encontrar frutas maduras [...] Creo que esto se debe a la imprevisión de los campesinos que siempre siembran menos de los que necesitan, así que van cogiendo inmediatamente los de buen tamaño". ${ }^{49}$ Para este viajero era tal la imprevisión de los habitantes rurales que, pese a que cada racimo daba decenas de plátanos, nunca tenían suficiente.Y era tal la complicidad del plátano con el ocio y la vida desenfadada de estos que se dejaba comer verde. Esta situación estaba vinculada a la falta de ambición. La ausencia de estaciones hacía innecesario planear, ahorrar y almacenar para sobrevivir, pero estas actividades mantenían su vigencia si de lo que se trataba era de prosperar en términos económicos. Para horror de los viajeros, los habitantes de las ardientes riberas de los ríos no aspiraban a tener una vida diferente; estaban satisfechos con que el futuro fuera una repetición incesante del presente que, a su vez, reproducía el pasado. Los viajeros describieron con asombro los pocos bienes que poseían los ribereños y lamentaron su desinterés por aumentarlos. Si algo les criticaron fue su conformismo con la vida que llevaban, su falta de ambición expresada en la renuncia a la acumulación.

El escritor boyacense José Joaquín Borda lamentó que “desconociendo el movimiento y las grandezas del mundo, [los bogas del Magdalena] fincan toda su ambición en una copa de aguardiente y unos racimos de plátano". ${ }^{50}$ Manuel Ancízar, periodista y miembro de la Comisión Corográfica, hizo eco del mismo argumento. Según él, el habitante de las tierras cálidas “es confiado, imprevisivo, su carácter inconstante, sus costumbres muelles y perezosas. ¿Para qué afanarse, ni meditar en el día de mañana, cuando los árboles le brindan y con sobra frutos espontáneos, los ríos le ofrecen fácil pesca y la tierra caliente le abruma con sus cosechas?". ${ }^{51}$ Estos son solo algunos de los defectos que los viajeros nacionales y extranjeros les atribuyeron a los habitantes de las riberas del Magdalena y otros ríos importantes para el transporte fluvial. El problema con el plátano y con la naturaleza tropical que simbolizaba era que actuaba como cómplice de este modo de vida:

48. Carl August Gosselman, Viaje por Colombia, 1825 y 1826 (Bogotá: Ediciones del Banco de la República, 1981) 113.

49. Holton 91.

50. José Joaquín Borda, "Seis horas en un champán", Museo de cuadros de costumbres, t. 2 (Bogotá: Biblioteca Banco Popular, 1973) 112.

51. Manuel Ancízar, Peregrinación de Alpha, vol. II (Bogotá:Talleres Tipográficos Banco Popular, 1984) 151. 
La banana constituye por sí sola un alimento completo, puede formar la base de la nutrición en el país, donde el hombre no se entrega a rudos trabajos.

El cultivo de la planta consiste en cortar los tallos agotados, que se utilizan como forraje, en desembarazar el tronco de los retoños demasiado numerosos y cortar las hojas marchitas. Sin más que estos cuidados, el mismo rincón de tierra producirá sin gran esfuerzo lo suficiente para satisfacer las necesidades de varias generaciones. ${ }^{52}$

Al ocio y la inactividad de los moradores, el plátano respondía con abundantes frutos, como recompensándolos. Era, por tanto, cómplice de la desidia, la indolencia y la pereza.

\section{El plátano como "no-cultivo"}

En el periodo de interés la mayoría de la población se dedicaba a la agricultura, una actividad que rara vez fue definida y en la que las fuentes incluyeron la recolección, la extracción y la producción de plantas útiles. Hacia mediados del siglo XIX fue más común la diferenciación entre extracción y producción, pero en la práctica ambas siguieron siendo tratadas como agricultura, pues lo que se privilegiaba era el aprovechamiento económico de los recursos vegetales..$^{53}$

Pese al atraso de la agricultura, su representación general fue positiva por ser considerada una actividad patriótica y una vía a la civilización. ${ }^{54}$ Sin embargo, hubo matices importantes. La recolección, la extracción de productos tropicales, la agricultura de subsistencia, la agricultura orientada al mercado interno y la producción para la exportación, fueron representadas en una escala civilizatoria ascendente. Las dos últimas eran las más valoradas, pues mientras la una contribuía a integrar el territorio nacional mediante la comercialización de excedentes, la otra generaba divisas. Además, ambas se prestaban mejor para el pago de impuestos, permitían un control más efectivo de la mano de obra e incentivaban una racionalidad económica más propia del capitalismo incipiente de entonces.

Hasta mediados del siglo XIX, en las descripciones de las tierras calientes predominó la negación del cultivo en favor de la recolección o la descripción de siembras de subsistencia en extremo descuidadas. En la segunda mitad del siglo XIX, con la "conquista" de estas tierras, ${ }^{55}$ ganaron visibilidad los cultivos alejados de los parámetros de las tierras frías, que incluían desyerbes más efectivos, surcos mejor delimitados, alturas más bajas y menor agrodiversidad. Ilustrativos resultan los casos del director de la Comisión Corográfica, Agustín Codazzi, quien justificó que los negros del Chocó no desyerbaran los terrenos por su extrema feracidad, ${ }^{56}$ y del abogado y

\section{Saffray, Viaje a Nueva Granada 156.}

53. Robledo Escobar.

54. Robledo Escobar.

55. Palacio Castañeda.

56. Agustín Codazzi, Geografia fisica y política de la Confederación Granadina, eds. Guido Barona Becerra y 
escritor Medardo Rivas, quien a finales de siglo explicó que al coger la cosecha "ya el rastrojo había crecido, y de pronto el monte volvía a tomar posesión del terreno, sin que quedase nada para el porvenir". ${ }^{57}$

Aun así, muchos de los sembrados de las tierras calientes siguieron pasando desapercibidos o subregistrados. El paisaje era leído como desorden y no como sistema agroforestal, ${ }^{58}$ por lo que eran poco valorados la biodiversidad, el aprovechamiento de las franjas del bosque y la dieta diversa que permitía. Los desmontes desaparecían devorados por una vegetación siempre creciente, de manera que los cultivos solían estar entremezclados con el matorral. Debido a esto, y a otros factores como la pequeña escala de los sembrados y la baja densidad poblacional, el trabajo humano solía pasar inadvertido.

En este contexto, cuando el plátano se sembraba "adecuadamente" era incluido en la agricultura de subsistencia y en la orientada al mercado interno por estar destinado al autoconsumo y al intercambio entre las regiones frías, templadas y cálidas. En esos casos era presentado como una muestra de la generosidad divina. Por ejemplo, el geógrafo y político Felipe Pérez lo consideró una “verdadera bendición de los países cálidos" y afirmó:

Nada más rico ni más hermoso que un platanal limpio, con sus calles tiradas a cordel, sus hojas enormes, batidas por la brisa y sus recargados racimos, desmintiendo, casi, el anatema de que el hombre tendrá que ganar el pan con el sudor de su frente. Rara en todo esta planta preciosa, hay que tumbarla para coger el fruto, pero un nuevo vástago brota luego del tronco, y ofrece una nueva cosecha..$^{59}$

Aquí aparece una comparación entre el pan —que Dios mandó a ganarse con el sudor de la frente- y el plátano - muestra de la munificencia divina-. Esta imagen del plátano también figura en la descripción que hizo Eugenio Díaz Castro de una fiesta del Corpus, en la que el centro de la escena del Paraíso "lo ocupaba una mata de plátano, con vástagos cargados de racimos de distintas edades. Debajo de las espléndidas hojas del plátano estaban dos chicos de parroquia molestados por los mosquitos, que representaban a Adán y Eva". ${ }^{\circ}$

Para Pérez y otros observadores, el plátano era una bendición de los países cálidos cuando se sembraba bien. El problema era que, desde su perspectiva, esto casi nunca sucedía. El plátano aparecía como un alimento de sujetos no-blancos con escasa vocación de trabajo y auspiciador de la cultura de la inmediatez, pues se daba

otros, vol. I, t. III (Bogotá: Universidad Nacional de Colombia, 2002) 405.

57. Rivas 35.

58. John A. Parrotta y otros, "The Historical, Environmental and Socio-economic Context of Forests and Tree-based Systems for Food Security and Nutrition", Forests and Food:Addressing Hunger and Nutrition Across Sustainable Landscapes, eds. BhaskarVira y otros (Cambridge: Open Book Publishers, 2015) 73-136.

59. Felipe Pérez, Episodios de un viaje (Bogotá: Editorial ABC, 1946) 36.

60. Díaz Castro 301. 
todo el año y requería una mínima transformación para ser consumido. El pan, en cambio, era presentado como un alimento europeo con un proceso de elaboración relativamente complejo y ejemplo de laboriosidad y previsión para el invierno. En los vapores del Magdalena se reproducía esta jerarquía, pues mientras a los viajeros les daban poco plátano, los bogas no recibían arroz ni pan. ${ }^{61}$ No obstante, resulta paradójico que quienes trabajaban eran aquellos que se alimentaban de plátano.

Para los viajeros nacionales y extranjeros, e incluso para criollos de fines de la colonia, el plátano era un "no-cultivo", en el sentido de que se daba abundantemente y sin mayores cuidados. Según el criollo Pedro Fermín deVargas, el plátano, el maíz, la carne y el pescado "lo encuentran ['las gentes de las tierras cálidas delVirreinato'] alrededor de sus habitaciones sin trabajo alguno". ${ }^{2}$ El comerciante británico John Steuart, quien visitó el país entre 1836 y 1837, afirmó que en el Magdalena solo se necesitaba “plantar unos cuantos vástagos o colinos de plátano, trabajar un poco los dos primeros años, para proveer las necesidades hasta que la fruta esté en su punto, o alimentarse con el excelente pescado". ${ }^{63}$ Como se ve, se requería trabajar no para producir plátano, sino para tener qué comer mientras este se daba solo.

Quizá fue Holton quien mejor sintetizó la condición de no-cultivo y su asociación con el no-trabajo. Según él, “el plátano ahorra al hombre más trabajo que el vapor. Le da la mayor cantidad de alimento por área de tierra cultivada y quizá el esfuerzo máximo es el de llevarlo a la boca después de asarlo". Acto seguido, afirmaba que "mi vecino Caldas dice que "la Nueva Granada sería algo si acabáramos con el plátano y con la caña de azúcar: esta es la madre de la embriaguez y aquel el padre de la pereza'", ${ }^{64}$

Sin requerir cuidados, una mata de plátano podía dar vástagos por décadas. Era tal la vagancia que supuestamente auspiciaba que la estrategia para mantener una variedad consistía en no hacer nada y esperar a que la planta se clonara a sí misma. La selección se limitaba a no sembrar ejemplares enfermos o afectados por insectos, lo cual contribuía a aumentar la resistencia futura a estos ataques. ${ }^{65}$

En síntesis, el plátano era un no-cultivo que no requería virtualmente ningún trabajo para dar sus frutos y que le daba sustento a la vida frugal — casi silvestrede los habitantes rurales de las tierras cálidas, de las cuales las riberas de los ríos, y especialmente las del Magdalena, fueron arquetípicas. Se asoció, por tanto, más con la recolección que con la producción propiamente dicha. Fue el caso de Codazzi, quien lamentó que los habitantes de las orillas del Cauca — “en lo general gente casi toda de color mezclada de diferentes modos"- - se conformaran con vivir de la pesca, la caza y el plátano. Según él, "la abundancia de animales silvestres que hay

61. Holton 58.

62. Pedro Fermín de Vargas, Pensamientos políticos, siglo XVII-siglo XVIII (Bogotá: Procultura, 1986) 25.

63. John Steuart, Narración de una expedición a la capital de la Nueva Granada y residencia allí de once meses (Bogotá en 1836-37) (Bogotá:Academia de Historia de Bogotá / Tercer Mundo Editores, 1989) 52.

64. Holton 21.

65. Carl L. Johannessen, "The Dispersal of Musa in Central America:The Domestication Process in Action", Annals of the Association of American Geographers 60.4 (1970): 693. 
en los montes de las orillas del Cauca proporcionan carnes diversas, y el plátano que no cesa de dar colosales racimos, es por sí solo suficiente para el mantenimiento de las familias que habitan esta comarca". ${ }^{66}$

En últimas, el problema con la recolección, la caza y la pesca era que sustentaban poblaciones indolentes, sin disciplina de trabajo, que pasaban los días "vegetando" y solo se levantaban de sus hamacas cuando el hambre los conminaba a ello. El rol civilizador de la recolección era nulo porque no transformaba el paisaje, no le permitía al Estado aumentar el control territorial ni recaudar impuestos y no desarrollaba una disciplina de trabajo ni actitudes de mercado. Asociar el plátano con la recolección significaba ligarlo a un modo de vida que, desde la perspectiva de los viajeros nacionales y extranjeros, nada le aportaba a la patria.

\section{De sostén de la vida a talanquera para la civilización}

La representación dominante del plátano de tierra caliente en la época evidencia la comprensión insuficiente de los modos de vida ribereños por parte de viajeros y miembros de las élites.

Por tardar más de un año en dar sus frutos, el plátano es un cultivo permanente. Si bien la previsión y el ahorro que implica su siembra debieron ser particularmente visibles, en las fuentes predominó la idea contraria. El plátano encarnó así una paradoja: al invisibilizar su condición de cultivo se le asociaba más con la recolección que con la producción, pero sustentaba un modo de vida más propio de las agriculturas orientadas a la subsistencia o al mercado interno. Mediante desmontes parciales, los pobladores combinaban cultivos de pequeña escala con la cría de animales, la pesca, la cacería y la recolección de productos silvestres. Además, recurrían a la boga o a la venta de alimentos — en mercados precariamente desarrollados - cuando necesitaban dinero, bien fuera para costear herramientas o productos como la sal, o para financiar actividades de socialización como las fiestas y las jornadas de juego.

Holton mostró la tensión entre la vida independiente y la participación en los mercados de bienes y trabajo. Sobre el boga planteó que "el machete, la canoa, los anzuelos, el sedal y la red son sus herramientas de trabajo, y si se añaden una camisa y una hamaca, se tendrá la lista completa de todas sus riquezas.Y no desea nada más. El pescado le cuesta menos trabajo que al campesino desenterrar papas con azadón en una loma, y los plátanos los consigue todavía más fácilmente" ${ }^{67}$ Sin embargo, luego explicó que el boga “es sobre todo un ser sensual. Le encantan los adornos y las camisas bordadas y no puede prescindir de los bailes y las borracheras. [...] Las viejas deudas y un par de juergas lo dejan sin centavo. Entonces tiene

66. Codazzi, Geografía fisica, vol. I, t. II, 144.

67. Holton 74. 
que volver a prestar hasta que agota ese recurso y no le queda más remedio que buscar trabajo otra vez en un champán". ${ }^{68}$

En efecto, más allá de las denuncias por la falta de ambición y de disciplina de trabajo, los propios contactos de los viajeros con los ribereños reflejaban la participación de estos en redes de intercambio comercial. No era esta, entonces, una economía natural. De igual forma, los cultivos, las gallinas y los marranos sustentaban modos de vida sencillos, pero más cercanos a una economía campesina que aprovechaba los recursos del entorno que a una economía de recolección itinerante en lugares supuestamente sobreabundantes.

¿Qué hizo que los viajeros leyeran de esta manera el modo de vida ribereño? Una explicación podría ser la frustración que les producía que sectores populares no realizaran trabajos físicos de sol a sol. A fin de cuentas, ese era uno de los principales mecanismos de distinción de las élites y debió ser chocante sentir que los ribereños se estaban "igualando". Pero, más allá de eso, el meollo del asunto podría estar en la determinación de los ribereños de mantener su independencia, basada en la abundancia tropical y particularmente en el plátano y el pescado. ${ }^{69} \mathrm{La}$ acuarela Orillas del Magdalena, de François Désiré Roulin, muestra una economía de subsistencia ribereña. ${ }^{70}$

Como primera medida, esta independencia afectaba la experiencia de viaje. Los no-blancos detentaban la propiedad - usualmente dada por la tradiciónsobre los recursos de las riberas de los ríos, los cuales administraban a su antojo. "Dueños" de las fuentes de alimento y de otras provisiones necesarias para el viaje, podían darse el lujo de negárselas a los blancos, quienes se veían obligados a rogar, pagar altas sumas de dinero o "robarlas" para sobrevivir. En 1838 Steuart explicó que los momposinos "rehusaban vendernos los artículos que deseábamos simplemente para no ser perturbados así las infelices criaturas no tuvieran un solo cuartillo". ${ }^{71}$ Todavía a finales del siglo XIX hubo quienes lamentaron la inutilidad del dinero en sus travesías fluviales, como el escritor y político argentino Miguel Cané, quien ante un frustrado intento de comprar huevos explicó que "con una calma desesperante, con apatía increíble contestan: 'No son para vender', y es necesario renunciar á toda insistencia, porque el dinero no tiene atractivo para esa gente sin necesidades". ${ }^{72}$ Como bogas, también detentaban la propiedad sobre el

68. Holton 88 .

69. Felipe Martínez Pinzón, "Celebración del plátano hartón: paz y trópico en Colombia”, 6 de mayo de 2013. https://www.razonpublica.com/index.php/cultura/artes-y-cultura/3720-celebracion-del-platano-harton-paz-y-tropico-en-colombia.html (25/02/2019).

70. François Désiré Roulin, "Bords de la Magdelaine. Ménage d'une famille de pêcheur” (acuarela sobre papel: 20,3 x 26,7 cm), 1823. BLAA, Bogotá, Colección de Arte, número de registro AP4080 https://www.banrepcultural.org/coleccion-de-arte/obra/bords-de-la-magdelaine-menage-dune-famille-de-pecheur-orillas-del-magdalena (25/01/2021).

71. Steuart 52.

72. Miguel Cané, En viaje (1881-1882) (Buenos Aires: Editorial Universitaria de Buenos Aires, 1968) 117. 
tiempo. Gracias a la abundancia tropical y especialmente al pescado y al plátano, podían suspender o abandonar su labor intempestivamente. Si renunciaban a la violencia para movilizarlos, los viajeros no tenían más alternativa que esperar.

Los viajeros estaban, entonces, a merced de los ribereños. Con su independencia, estos subvertían de facto las jerarquías. Así, gentes consideradas de menor condición social y racial, muchas veces subordinadas por un vínculo laboral informal, podían darse el lujo de ignorar las órdenes que se les impartían o de cumplirlas a su manera. Como lo explica Martínez Pinzón, en el tránsito por las tierras calientes se daba "el encuentro entre dos razas separadas ideológicamente en la paleta neocolonial, el blanco y el zambo, el depositario de la misión civilizadora y el último escalafón en la jerarquía de las castas". ${ }^{73}$ Que en ese encuentro las jerarquías no fueran absolutas no solo golpeaba el ego de hombres blancos acostumbrados a un trato distinto, sino que ponía en jaque la supuesta inevitabilidad de la civilización. Si la sobreabundancia les permitía a los ribereños marginarse de las iniciativas económicas venidas de arriba — en un doble sentido: de las cordilleras y de las élites_entonces sus pasiones y vicios perpetuarían el atraso en el que se encontraban.

Como segunda medida, la independencia de los ribereños amenazaba la explotación de los innumerables recursos de tierra caliente, en la cual sectores de las élites - especialmente las liberales de la segunda mitad del siglo XIX - tenían intereses económicos directos. Desde esta perspectiva, los ribereños eran culpables de que estas tierras, que tenían las mejores condiciones para impulsar el progreso nacional — abundancia de recursos, conectividad, cercanía a puertos-, permanecieran casi inexplotadas.

Para los viajeros nacionales y extranjeros, la solución al clima malsano de las tierras calientes y al mal temperamento de sus habitantes recaía, sobre todo, en el trabajo:

La acción lenta del tiempo va mejorando estas llanuras y preparándolas para futura mansión de los hombres [...]; y cuando el hacha resuene en la selva y la derribe, se completará la obra de sanidad, domada la salvaje naturaleza, y lo que ahora es sepulcro seguro del trabajador aislado, se verá en las edades venideras, convertido en campos abiertos, hermoseados por el cultivo y las habitaciones, y fertilizados por el curso de ríos caudalosos, que al mismo tiempo servirán de canales para el rápido transporte de las riquezas. ${ }^{74}$

La vía más segura a la civilización era el trabajo duro, constante y planificado, propio de las labores agrícolas en toda regla. Por la abundancia de recursos y las mayores facilidades de transporte, los habitantes de tierra caliente debían dedicarse a la agroexportación. Hasta mediados del siglo XIX, el origen extractivo de los productos exportables fue rara vez discutido y los observadores se limitaron a

73. Felipe Martínez Pinzón, “Tránsitos por el río Magdalena: el boga, el blanco y las contradicciones del liberalismo colombiano de mediados del siglo XIX”, Estudios de Literatura Colombiana 29 (2011): 19.

74. Agustín Codazzi, Geografía física y política de la Confederación Granadina, eds. Guido Barona Becerra y otros, vol.V (Bogotá: Universidad Nacional de Colombia, 2004) 362. 
desear que los ribereños contribuyeran a integrar el país a los mercados internacionales. Con el auge del tabaco y posteriormente del café, esta situación cambió. No obstante, los viajeros, sobre todo los nacionales, criticaron que los ribereños se aferraran a sus vidas supuestamente vegetativas, libres de necesidades pero también de obligaciones, y se negaran a servir como mano de obra de las haciendas, muchas de ellas fundadas por ellos mismos en el marco de la colonización de vertiente cundinamarquesa y en menor medida antioqueña. José María Samper, un periodista y político colombiano que incursionó en el negocio del tabaco, lo describió magistralmente:

Pero observad esta choza miserable que se destaca en la orilla del río [...], a la vera del bosque virgen y de un pequeño platanal y un maizal. Debajo de un árbol se ve pendiente una hamaca [...] allí reposa el voluptuoso príncipe de la soledad, soñoliento, indolente, libre y salvaje como el árbol que le da sombra. Cerca del rancho se ve, secándose al sol sobre una barbacoa, el chinchorro o la atarraya con que pesca el zambo, a la sombra del mismo rancho penden de las vigas algunos racimos de plátanos verdes y maduros, y al pie de la barranca se balancea entre mimbres y gramíneas la pequeña piragua que le sirve al semi-salvaje para pescar [...].¿Os parecerá extraño que un hombre viva en esa indolencia, sin religión, sin relaciones sociales, libre de toda autoridad, contento con su suerte miserable y sin ninguna aspiración? Él se cree más dichoso que nadie, porque no tiene los deberes del ciudadano ni las necesidades de la civilización. Su platanar eterno, su maizal y su yucal (que son casi su lujo), su hamaca, su red y su canoa, le bastan para vivir. Cuando necesita sal, plomo para su red, un machete, un cuchillo, un azadón o algún pedazo de coleta u otro género, llena su piragua de plátanos, yucas y pescado seco, va a venderlos a la más cercana villa o parroquia, se provee de lo que necesita y vuelve a su vida de indolente reposo. ${ }^{75}$

Desde la perspectiva de Samper, el "príncipe de la soledad", en su libertad mal entendida, se privaba voluntariamente de ejercer su ciudadanía y de aportar al proyecto nacional. En un país que sufría por la falta de brazos, no concebía que se negara a prestarlos en beneficio de la civilización.

Por estas razones, los viajeros no solo les atribuyeron a los ribereños un modo de vida más cercano al de la recolección que al de la subsistencia, sino que a esta última la valoraron de forma negativa a pesar de que la defendieron para regiones como la andina. ${ }^{76}$ En la práctica - y aunque ignoramos si ellos lo conceptualizaron así- el plátano constituyó un elemento de resistencia, al darles a los ribereños el sustento para mantener su independencia. Lo que para unos operaba como elemento de resistencia, para otros - las élites y los viajeros - no era otra cosa que una atadura al pasado, una talanquera que debía superarse para civilizar las tierras calientes y sus habitantes.

No obstante, en la defensa de la independencia propia de una economía de subsistencia había una racionalidad económica coherente. Aunque les pesara a los

75. José María Samper, Ensayos sobre las revoluciones políticas y la condición social de las repúblicas colombianas. Con un apéndice sobre la orografía y la población de la Confederación Granadina (Bogotá: Editorial Centro, 1945) 99.

76. Manuel Ancízar, Peregrinación de Alpha, vol. I (Bogotá:Talleres Tipográficos Banco Popular, 1984). 
viajeros y a otros observadores de la época, los ribereños no tenían mayores incentivos para aumentar su producción. Primero, porque no tenían dónde venderla, pues la población circundante era reducida y pobre y los centros urbanos estaban apartados tanto por la distancia como por la falta de infraestructura. Segundo, porque tampoco tenían mucho qué comprar, ya que los bienes de consumo eran escasos y las condiciones ambientales de su entorno hacían imposible el disfrute de muchos de ellos. Tercero, porque con el auge agroexportador crecía el miedo a la usurpación de tierras. Este riesgo, agravado por la falta de títulos de propiedad, posiblemente los inhibía de construir mejoras y de elevar la productividad a su máximo potencial. ${ }^{77}$

La alternativa de vincularse a las haciendas tampoco debía sonar muy halagadora. Estas funcionaban con base en sistemas de endeude efectivos para fijar la mano de obra, pero no para garantizar condiciones de vida mejores que las de una economía de subsistencia. Asimismo, a los estancieros se les asignaba una parcela para el pancoger, pero solían tener vedado el principal producto de la hacienda, y con frecuencia debían prestar servicios que no habían acordado con el hacendado, so pena de expulsión. Familias sin tierra en regiones donde esta era escasa tenían un incentivo mayor para vincularse a la hacienda, pero para los ribereños que disfrutaban de un pedazo de tierra, aunque no tuvieran un título legal, esta opción debió aparecer como una atadura sin mayores beneficios. ${ }^{78}$

\section{Reflexiones finales}

Tras tres siglos de virtual aislamiento, las autoridades republicanas decimonónicas ansiaban fortalecer los intercambios con Europa y Estados Unidos, pero carecían de infraestructura adecuada para esto. Los viajeros nacionales y extranjeros que recorrieron el bajo y medio Magdalena realizaron viajes largos e inciertos en bongos, champanes o, a lo sumo, desde 1827 y cuando estaba funcionando, en vapor. Los relatos de estos recorridos resultan similares al que hiciera Marlow en su viaje al Corazón de las tinieblas, la novela de Joseph Conrad. En ambos casos, se describe el hombre civilizado que se adentra en un mundo desconocido, impredecible y (semi)salvaje, en el que las fieras conviven con los seres humanos y la vegetación todo lo devora.

Estas embarcaciones artesanales que surcaban el río Magdalena eran movidas por bogas, esos "beduinos de las aguas" a los que encontraban ociosos y semisalvajes. ${ }^{79}$ Los viajeros solían quejarse — con resignación, molestia e incluso envidia- de la escasa dedicación al trabajo de estos pobladores, y los describieron echados en su hamaca, seguros de que su ociosidad sería recompensada con una buena ración de pescado y plátano. De estos dos productos, el último concentró su atención.

77. Fabio Sánchez y otros, "Land Conflicts, Property Rights, and the Rise of the Export Economy in Colombia, 1850-1925”, The Journal of Economic History 70.2 (2016): 396. DOI: 10.1017/ S002205071000032X.

78. Martínez Pinzón, "Celebración del plátano hartón”.

79. Pérez 49. 
La representación del plátano fue construida a partir de varias imágenes en las que apareció como la quintaesencia del trópico que, en su sobreabundancia, tornaba la fertilidad natural en infertilidad cultural; como "no-cultivo", cómplice de la vida casi silvestre de los habitantes de las tierras cálidas, como símbolo del ocio racializado y talanquera para la civilización.

A partir de estas imágenes, el plátano fue representado como un marcador de la diferencia entre el mundo civilizado y aquel en el que todo estaba por hacerse. Este producto permitía diferenciar el "nosotros" del "otros" en las riberas del río en términos territoriales y humanos. En cuanto a lo primero, la diferencia entre las tierras templadas - temperate - europeas y las tierras calientes americanas fue simbolizada por algunos viajeros a partir del pan y el plátano. En cuanto a lo segundo, la frontera estuvo dada por las prácticas de consumo, particularmente entre viajeros y bogas, pero especialmente por las de producción.

En síntesis, no vivir del plátano daba superioridad moral, a la vez que reflejaba una mayor civilización. A su paso por las riberas del Magdalena los viajeros representaron al plátano como símbolo de un modo de vida: el del morador de las selvas, marginado de la vida en sociedad, con una mínima participación en los circuitos mercantiles y feliz en medio de una escasez que nada le aportaba al progreso de la nación. Dicho modo de vida no contribuía a la acumulación, ni de los sujetos subalternos ni de los empresarios que aspiraban a tenerlos como fuerza de trabajo en sus haciendas.

El problema del plátano era, entonces, que constituía una atadura con el pasado. Dado que obstaculizaba la abundancia de brazos y el desmonte de las zonas selváticas, necesarios para la producción de tabaco y posteriormente de café, constituía un freno a la civilización. Por lo tanto, el plátano también encarnaba el miedo al futuro, a fracasar en la construcción de la nación, de lo cual se culpaba al trópico, a su gente y a la manera como está (mal)utilizaba la rica naturaleza americana.

La mirada de los viajeros nacionales y extranjeros pertenecientes a las élites o conectados con ellas fue fundamentalmente de una sola vía: les exigían a los ribereños cumplir sus deberes como ciudadanos de una nación recientemente liberada que necesitaba de su trabajo para alcanzar la civilización, pero no veían los deberes que incumplía el Estado. Querían que produjeran excedentes, pero omitían las dificultades que tenían para venderlos; pretendían que ahorraran y acumularan, pero ignoraban que no había mucho qué comprar; querían que invirtieran en sus tierras y las dotaran con mejoras, pero callaban ante la falta de títulos de propiedad y el despojo que acompañó el auge agroexportador. Los viajeros no se preguntaron qué ganaba un habitante del Magdalena con vincularse a la economía agroexportadora y menos aún se preguntaron qué perdía. En consecuencia, no pudieron - o no quisieron - ver que el plátano, y lo que este representaba, entrañaba una forma de resistencia a su proyecto civilizador. 


\section{Fuentes}

\section{Impresas}

Ancízar, Manuel. Peregrinación de Alpha.Volúmenes I y II. Bogotá:Talleres Tipográficos Banco Popular, 1984.

Borda, José Joaquín. "Seis horas en un champán". Museo de cuadros de costumbres. Tomo 2. Bogotá: Biblioteca Banco Popular, 1973.

Boussingault, Jean Baptiste. Memorias.Volumen 2. Bogotá:Banco de la República, 1985. Briceño Briceño, A. "La siembra del trigo". Museo de cuadros de costumbres. Tomo 3. Bogotá: Biblioteca Banco Popular, 1973.

Caldas, Francisco José de. "Memoria sobre la nivelación de las plantas que se cultivan en la vecindad del Ecuador". Obras completas de Francisco José de Caldas. Publicadas por la Universidad Nacional de Colombia como homenaje con motivo del sesquicentenario de su muerte. Bogotá: Imprenta Nacional, 1966.

Cané, Miguel. En viaje (1881-1882). Buenos Aires: Editorial Universitaria de Buenos Aires, 1968.

Codazzi, Agustín. Geografía física y política de la Confederación Granadina. Eds. Guido Barona Becerra y otros. Volumen I. Tomos II y III. Bogotá: Universidad Nacional de Colombia, 2002.

Geografía fisica y política de la Confederación Granadina. Eds. Guido Barona Becerra y otros.Volumen V. Bogotá: Universidad Nacional de Colombia, 2004.

Díaz Castro, Eugenio. Manuela. Bogotá: Panamericana, 2004.

Finestrad, Fr. Joaquín de. El vasallo instruido en el estado del Nuevo Reino de Granada y en sus respectivas obligaciones. Bogotá: Universidad Nacional de Colombia, 2001.

Gosselman, Carl August. Viaje por Colombia, 1825 y 1826. Bogotá: Ediciones del Banco de la República, 1981.

Hettner, Alfred. Viajes por los Andes colombianos (1882-1884). Bogotá:Talleres Gráficos del Banco de la República, Archivo de la Economía Nacional, 1976.

Holton, Isaac F. La Nueva Granada: veinte meses en los Andes. Bogotá: Ediciones del Banco de la República, 1981.

Humboldt, Alexander von y Aimé Bonpland. Ideas para una geografía de las plantas más un cuadro de la naturaleza de los países tropicales. Bogotá:Jardín Botánico José Celestino Mutis, 1985.

Moyne, Augusto Le. Viaje y estancia en la Nueva Granada. Bogotá: Ediciones Guadalupe, 1969.

Pérez, Felipe. Episodios de un viaje. Bogotá: Editorial ABC, 1946.

Rivas, Medardo. Los trabajadores de tierra caliente. Bogotá: Incunables, 1983.

Saffray, Charles. Viaje a Nueva Granada. Bogotá: Ministerio de Educación Nacional, 1948.

Samper, José María. Ensayos sobre las revoluciones políticas y la condición social de las repúblicas colombianas. Con un apéndice sobre la orografía y la población de la 
Confederación Granadina. Bogotá: Editorial Centro, 1945.

Samper, Miguel. La miseria en Bogotá y otros escritos. Bogotá: Biblioteca Universitaria de Cultura Colombiana, 1969.

Steuart, John. Narración de una expedición a la capital de la Nueva Granada y residencia allí de once meses (Bogotá en 1836-37). Bogotá: Academia de Historia de Bogotá / Tercer Mundo Editores, 1989.

Vargas, Pedro Fermín de. Pensamientos políticos, siglo XVII - siglo XVIII. Bogotá: Procultura, 1986.

\section{Internet}

https://www.agronet.gov.co

https://www.razonpublica.com (2013)

\section{Bibliografía}

Andreouli, Eleni y Xenia Chryssochoou. "Social Representations of National Identity in Culturally Diverse Societies". The Cambridge Handbook of Social Representations. Eds. Gordon Sammut y otros. Cambridge: Cambridge University Press, 2015.

Appelbaum, Nancy P. Dos plazas y una nación. Raza y colonización en Riosucio, Caldas, 1846-1948. Bogotá: Instituto Colombiano de Antropología e Historia / Universidad de los Andes / Universidad del Rosario, 2007.

- Mapping the Country of Regions. The Chorographic Commission of Nineteenth-Century Colombia. Chapel Hill:The University of North Carolina Press, 2016.

Arias Vanegas, Julio. Nación y diferencia en el siglo XIX colombiano. Orden nacional, racialismo y taxonomías poblacionales. Bogotá: Ediciones Uniandes, 2005.

Burke, Peter. Visto y no visto. El uso de la imagen como documento histórico. Barcelona: Crítica, 2001.

Hall, Stuart. "The Work of Representation”. Representation: Cultural Representations and Signifying Practices. Ed. Stuart Hall. Londres: Sage Publications, 1997.

Jaramillo Uribe, Jaime. "La visión de los otros. Colombia vista por observadores extranjeros en el siglo XIX”. Historia Crítica 24 (2002): 7-21. DOI: 10.7440/histcrit24.2002.01.

Johannessen, Carl L. "The Dispersal of Musa in Central America:The Domestication Process in Action". Annals of the Association of American Geographers 60.4 (1970): 689-699.

Korsmeyer, Carolyn. Ed. The Taste Culture Reader. Experiencing Food and Drink. Oxford / New York: Berg Publishers, 2005.

Lasso, Marixa. Myths of Harmony. Race and Republicanism during the Age of Revolution, Colombia 1795-1831. Pittsburgh: University of Pittsburgh Press, 2007.

Martínez Pinzón, Felipe. "Tránsitos por el río Magdalena: El boga, el blanco y las contradicciones del liberalismo colombiano de mediados del siglo XIX”. 
Estudios de Literatura Colombiana 29 (2011): 17-41.

- Una cultura de invernadero:Trópico y civilización en Colombia (1808-1928). Madrid: Iberoamericana, 2016.

Melo, Jorge Orlando. "La mirada de los franceses: Colombia en los libros de viaje durante el siglo XIX”. 2001.http://jorgeorlandomelo.com/mirada_franceses.htm (25/06/2020).

Moscovici, Serge. "Notes towards a description of Social Representations”. European Journal of Social Psychology 18 (1988): 211-250.

Nieto Villamizar, María Camila y María Riaño Pradilla. Esclavos, negros libres y bogas en la literatura del siglo XIX. Bogotá: Ediciones Uniandes, 2011.

Ocampo, José Antonio. Colombia y la economía mundial, 1830-1910. Bogotá: Siglo XXI Editores, 1984.

Palacio Castañeda, Germán A. Fiebre de tierra caliente. Una historia ambiental de Colombia, 1850-1930. Bogotá: Universidad Nacional de Colombia / ILSA, 2006.

Parrotta, John A. y otros. “The Historical, Environmental and Socio-economic Context of Forests and Tree-based Systems for Food Security and Nutrition”. Forests and Food: Addressing Hunger and Nutrition Across Sustainable Landscapes. Eds. BhaskarVira y otros. Cambridge: Open Book Publishers, 2015.

Patiño,Víctor Manuel. "Plátanos y bananos en América equinoccial”. Revista Colombiana de Antropología VII (1958): 297-337.

Pratt, Mary Louise. Imperial Eyes. Travel Writing and Transculturation. Londres / Nueva York: Routledge, 1994.

Robledo Escobar, Natalia. "Labrar para civilizar y ser civilizado: representaciones sociales sobre el campo, la agricultura y los agricultores del actual territorio colombiano en el periodo comprendido entre 1780 y 1866 ". Tesis de doctorado en Antropología, Universidad de los Andes, 2017.

Rojas, Cristina. Civilización y violencia. La búsqueda de la identidad en la Colombia del siglo XIX. Bogotá: Pontificia Universidad Javeriana / Editorial Norma, 2001.

Saldarriaga, Gregorio. "Musas en el paraíso: apropiaciones del plátano por parte de españoles e indígenas. Nuevo Reino de Granada, siglos XVI y XVII". Revista do Instituto Histórico e Geográfico do Pará 7 (2020): 14-26.

Sánchez, Fabio y otros. "Land Conflicts, Property Rights, and the Rise of the Export Economy in Colombia, 1850-1925”. The Journal of Economic History 70.2 (2016): 378-399. DOI: 10.1017/S002205071000032X.

Soluri, John. Culturas bananeras: producción, consumo y transformaciones socioambientales. Bogotá: Siglo del Hombre Editores / Universidad Nacional de Colombia, 2013.

Stepan, Nancy Leys. Picturing tropical nature. Londres: Reaktion Books, 2001.

Taussig, Michael. Chamanismo, colonialismo y el hombre salvaje. Un estudio sobre el terror y la curación. Bogotá: Editorial Norma, 2002.

Villegas Vélez, Álvaro. "Heterologías y nación: proyectos letrados y alteridad radical en la Colombia decimonónica”. Signo y Pensamiento 27.53 (2008): 24-37. 